\title{
Evidence of a Functional Relationship between the Nucleus Accumbens Shell and Lateral Hypothalamus Subserving the Control of Feeding Behavior
}

\author{
Thomas R. Stratford and Ann E. Kelley \\ Department of Psychiatry, University of Wisconsin-Madison Medical School, Madison, Wisconsin 53719
}

Inhibition of neurons in the nucleus accumbens shell (AcbSh) with local injections of GABA agonists or glutamate antagonists elicits an intense, but specific, feeding response resembling that seen after stimulation of the lateral hypothalamus (LH). To help characterize the contribution of the LH to the expression of AcbSh-mediated feeding, we used the immunohistochemical detection of the nuclear protein Fos to determine whether inhibition of AcbSh cells results in an activation of $\mathrm{LH}$ neurons. Injections of the $\mathrm{GABA}_{\mathrm{A}}$ agonist muscimol into the AcbSh greatly increased the number of cells exhibiting Fos-like immunoreactivity in the $\mathrm{LH}$, as well as in the lateral septum, paraventricular hypothalamic nucleus, ventral tegmental area, substantia nigra pars compacta, and nucleus of the solitary tract. Blocking activation of $\mathrm{LH}$ neurons with the selective NMDA receptor blocker $\mathrm{D}(-)-\mathrm{AP}-5$ is known to suppress deprivationinduced feeding. We found that injections of $D(-)$-AP5 into the
LH also dose-dependently suppressed AcbSh-mediated feeding.

It is likely that inhibition of GABAergic neurons in the AcbSh is responsible for eliciting this feeding. If a behaviorally relevant GABAergic projection terminates in the $\mathrm{LH}$, we should be able to mimic the effects seen after inhibition of the projection neurons by applying a GABA receptor blocker to the area. However, injections of the $\mathrm{GABA}_{A}$ receptor blocker bicuculline or the $\mathrm{GABA}_{\mathrm{B}}$ receptor blocker saclofen did not significantly affect food intake. Thus, it appears that the expression of the feeding response depends on an NMDA-preferring receptormediated activation of $\mathrm{LH}$ neurons and is not the result of disinhibiting $\mathrm{LH}$ cells by disrupting transmission at GABA synapses.

Key words: nucleus accumbens shell; lateral hypothalamus; feeding behavior; c-fos; GABA; NMDA; $D(-)-A P-5$
Although it is well known that the nucleus accumbens plays a critical role in the regulation of appetitive behavior (Salamone, 1994; Ikemoto and Panksepp, 1996), several recent studies have implicated the shell subregion (AcbSh) as an important component of a neural system specifically involved in the mediation of feeding behavior. Inhibition of neurons in the AcbSh by administration of excitatory amino acid antagonists (MaldonadoIrizarry et al., 1995; Stratford et al., 1998) or GABA agonists (Stratford and Kelley, 1997b) elicits intense feeding in satiated rats. These treatments appear to affect feeding behavior specifically, because they do not increase water intake, noningestive gnawing, or locomotor activity (Stratford et al., 1998). As such, the effect does not appear to be the result of a general behavioral activation.

The majority of cells projecting from the AcbSh are medium spiny neurons that use GABA as a neurotransmitter (Meredith et al., 1993), and both symmetric inhibitory GABAergic terminals and neurochemically uncharacterized asymmetric (presumably excitatory) terminals have been shown in apposition to the axon hillock of these neurons (Meredith and Wouterlood, 1991), placing them in a position to exert a powerful influence on the output of these cells. It follows that, if we inhibit GABAergic AcbSh projection neurons through actions at glutamate and GABA receptors located on those cells, then disrupting GABA transmis-

\footnotetext{
Received May 10, 1999; revised Sept. 10, 1999; accepted Oct. 1, 1999.

This work was supported by National Institute on Drug Abuse Grant DA04788.

Correspondence should be addressed to Thomas R. Stratford at his present address: Neuropsychiatric Research Institute, 700 First Avenue South, Fargo, ND 58103. E-mail: tstratford@nrifargo.com.

Copyright (C) 1999 Society for Neuroscience 0270-6474/99/1911040-09\$05.00/0
}

sion in the terminal fields of those neurons may also elicit feeding. Currently, the locations of the relevant terminal fields are unknown; however, a likely candidate appears to be the lateral hypothalamus $(\mathrm{LH})$. In the paper that initially described the elicitation of feeding from the AcbSh, the authors noted that the intensity of the feeding reminded them of that seen after stimulation of the LH. They subsequently demonstrated a functional relationship between these two brain regions by showing that AcbSh-mediated feeding could be attenuated by injections of the $\mathrm{GABA}_{\mathrm{A}}$ receptor agonist muscimol into the $\mathrm{LH}$ (MaldonadoIrizarry et al., 1995). Furthermore, it is well known that neurons in the AcbSh project directly to the LH (Heimer et al., 1991; Zahm and Brog, 1992; Kirouac and Ganguly, 1995) and that electrical (Delgado and Anand, 1953) or chemical (Stanley et al., 1993a,b) stimulation of LH neurons can induce robust feeding in satiated animals.

The following series of studies was designed to investigate further the nature of the relationship between these two brain regions. In experiment 1 , we used the immunohistochemical detection of the c-fos gene product Fos to explore the possibility that injections of muscimol into the AcbSh increase the firing rate of neurons in the LH. Experiment 2 involved investigating whether disrupting glutamate transmission in the LH by blocking NMDA receptors can suppress AcbSh-mediated feeding as it has been shown to do to deprivation-induced feeding (Stanley et al., 1996). Finally, we examined the effect blocking GABA receptors in the LH had on food intake in an attempt to determine whether GABAergic fibers terminating in the region contribute to a tonic inhibition of $\mathrm{LH}$ neurons that participate in the control of feeding behavior. 


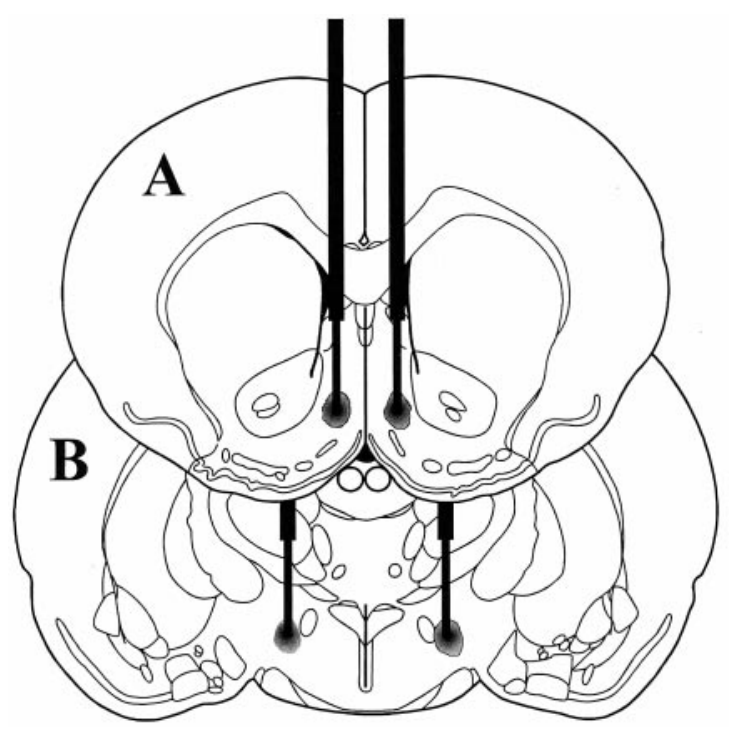

Figure 1. Schematic representation of bilateral injection sites centered in AcbSh $(A)$ and perifornical LH $(B)$ (modified from Paxinos and Watson, 1997).

Parts of this paper have been published previously in abstract form (Stratford and Kelley, 1997a)

\section{MATERIALS AND METHODS}

Subjects. Male Sprague Dawley rats (Harlan, Madison, WI) weighing between 280 and $300 \mathrm{gm}$ at the time of surgery were group-housed in acrylic cages and maintained in a temperature- $\left(\sim 21^{\circ} \mathrm{C}\right)$ and light- $(12 \mathrm{hr}$ light/dark) controlled environment with food (Harlan Teklab Rat Diet 7001) and acidified tap water available ad libitum.

Surgery. The rats were anesthetized with a mixture of ketamine $\mathrm{HCl}$ and xylazine (100 and $10 \mathrm{mg} / \mathrm{kg}$, respectively; Sigma, St. Louis, MO), and bilateral 23 gauge stainless steel guide cannulas were implanted using standard, flat-skull stereotaxic techniques. In experiment 1 , eight rats received guide cannulas aimed at the AcbSh using the following coordinates: anteroposterior (AP), 1.4; lateromedial (LM), \pm 0.8 ; dorsoventral (DV), -5.5 (in millimeters from bregma; Paxinos and Watson, 1997). For experiment 2, six rats received guide cannulas aimed at the LH (AP, $-2.5 ; \mathrm{LM}, \pm 1.8 ; \mathrm{DV},-6.0$ ). For the third experiment, guide cannulas aimed at both the AcbSh and the LH were implanted in eight rats. All of the guide cannulas were held in place using stainless steel screws and denture lining material, and a stainless steel obturator was inserted into the lumen of each cannula to help maintain patency. Each rat received a prophylactic intramuscular injection of sterile penicillin $(\sim 40,000 \mathrm{U}$; Flo-Cillin; Fort Dodge Laboratories, Inc., Fort Dodge, IA) after surgery and was allowed to recover at least $7 \mathrm{~d}$ before the start of behavioral testing.

Intracerebral injections. To acclimate the rats to the test procedure, the obturators were removed, and a 30 gauge injection cannula, extending 2.5 $\mathrm{mm}$ beyond the ventral tip of the guide, was inserted into each guide cannula on 3 consecutive days. The obturators were replaced, and the rats were placed in the test cages $(42 \times 20 \mathrm{~cm})$ for $120 \mathrm{~min}$. On the final acclimation day, each rat received a $0.5 \mu \mathrm{l}$ intracerebral injection of 0.15 M saline. On test days, each rat received simultaneous bilateral injections of $0.5 \mu \mathrm{l}$ of drug or the $0.15 \mathrm{M}$ saline vehicle at a rate of $0.32 \mu \mathrm{l} / \mathrm{min}$. After the infusion, the injection cannulas were left in place for an additional 60 sec to minimize leakage up the cannula track. At least $48 \mathrm{hr}$ were allowed between injections.

Drugs. Muscimol was obtained from Sigma (St. Louis, MO). Bicuculline methbromide, saclofen, and $\mathrm{D}(-)$-2-amino-5-phosphonopentanoic acid (D(-)-AP-5) were obtained from Research Biochemicals (Natick, MA). All drugs were dissolved in sterile $0.15 \mathrm{M}$ saline.

Experimental design. In experiment 1, we investigated the effects intraAcbSh injections of muscimol had on the expression of c-fos in the LH. Rats received guide cannulas aimed at the AcbSh (as described above) and were allowed to recover for $7 \mathrm{~d}$. During that time, the rats were handled daily and were acclimated to the test cages and injection proce- dure. To ensure that the treatment would increase feeding behavior, food and water intakes were recorded after injections of muscimol or the saline vehicle into the AcbSh. On the seventh day, all of the rats received simultaneous, bilateral $0.5 \mu \mathrm{l}$ injections of sterile $0.15 \mathrm{M}$ saline into the AcbSh. The rats were placed in test cages with a preweighed quantity of food and a graduated bottle containing tap water available, and food and water intakes were recorded at 30,60, and $120 \mathrm{~min}$. Three days later, all of the rats received bilateral injections of muscimol $(100 \mathrm{ng} / 0.5 \mu \mathrm{l})$ into the AcbSh, and food and water intake were recorded as before. Five days later, half of the rats received bilateral injections of saline and half received bilateral injections of muscimol $(100 \mathrm{ng} / 0.5 \mu \mathrm{l})$ into the AcbSh and were placed in the test cages without food or water present. The rats remained in the test cages for $90 \mathrm{~min}$, at which time they were anesthetized and perfused as described below.

Experiment 2 was designed to determine whether blocking glutamate transmission at NMDA receptors in the perifornical hypothalamus could suppress the intense feeding elicited by bilateral injections of muscimol into the AcbSh. Rats received bilateral guide cannulas aimed at both the AcbSh and the perifornical LH. Food and water intake were recorded after simultaneous, bilateral injections of vehicle at both sites or after injections of $438 \mathrm{pmol}(50 \mathrm{ng}$ ) of muscimol into the AcbSh and 0, 0.1, 1.0, or $10.0 \mathrm{nmol}$ of $\mathrm{D}(-)$-AP-5 into the LH. Treatment order was counterbalanced, and the rats were allowed at least $48 \mathrm{hr}$ between injections.

In experiment 3 , we investigated the possibility that blocking GABA receptors in the perifornical $\mathrm{LH}$ could increase food intake in satiated rats. Guide cannulas aimed at the perifornical $\mathrm{LH}$ were implanted into rats, they were allowed to recover for 1 week, and they were acclimated to the injection and test procedures as described above. On test days, the rats received bilateral injections of either vehicle or $10,50,100$, or $200 \mathrm{ng}$ of the selective $\mathrm{GABA}_{\mathrm{A}}$ receptor blocker bicuculline, and food and water intake were recorded at 30,60, and $120 \mathrm{~min}$. Treatment was counterbalanced, and at least $48 \mathrm{hr}$ were allowed between injections. After the rats had been tested with each dose of bicuculline, all of the rats were tested with a single dose $(500 \mathrm{ng})$ of the selective $\mathrm{GABA}_{\mathrm{B}}$ receptor blocker saclofen.

Histology. After behavioral testing, all of the animals were deeply anesthetized using sodium pentobarbital and were perfused transcardially with $50 \mathrm{ml}$ of a $0.15 \mathrm{M}$ saline solution, followed immediately by 500 $\mathrm{ml}$ of a $10 \%$ buffered formalin solution. The brains of rats in the c-fos study were blocked between the AcbSh and the LH, and the caudal fragment was post-fixed in the formalin solution for $2-3 \mathrm{hr}$, moved to $20 \%$ sucrose in $0.01 \mathrm{M}$ phosphate buffer at $4^{\circ} \mathrm{C}$ for $48 \mathrm{hr}$, and then immunohistochemically processed. The rostral brain fragments of the rats in the c-fos study and the brains of the rats in the feeding studies were removed and stored in fixative for at least 1 week. They were then frozen, and $60 \mu \mathrm{m}$ coronal sections were taken throughout the extent of the injection sites. The sections were stained with cresyl violet, and the injection sites were examined for placement accuracy and excessive damage. Data from rats with misplaced cannulas were not included in the analyses.

Immunocytochemistry. The brains were frozen quickly with a chemical freeze spray (Freeze-It; Chemtronics Inc., Kennesaw, GA), and 30- $\mu$ mthick coronal sections were taken from the level of the median preoptic nucleus to the caudal pole of the interpeduncular nucleus and also throughout the extent of the nucleus of the solitary tract (NTS). Every other section was placed in a blocking serum composed of 0.01 M PBS, pH 7.2, containing 10\% normal goat serum (NGS) (Vector Laboratories, Burlingame, CA) and 0.3\% Triton X-100 (Sigma) for $30 \mathrm{~min}$. The sections were rinsed in PBS and incubated on a rotary shaker table for 20 $\mathrm{hr}$ at $4^{\circ} \mathrm{C}$ in a polyclonal primary antibody (rabbit anti-Fos, diluted 1:50,000 with 0.01 M PBS containing 4\% NGS; Oncogene Research Products, Cambridge, MA). The sections were rinsed again in PBS and were processed using a Vectastain Elite ABC kit (Vector Laboratories). The sections were incubated in the biotinylated goat anti-rabbit secondary antibody (containing 4\% NGS) for $60 \mathrm{~min}$ at room temperature, were rinsed in PBS (three times for $10 \mathrm{~min}$ each), and were incubated in the avidin-biotin complex solution for $60 \mathrm{~min}$. After another series of rinses in PBS, the peroxidase was visualized by incubating the tissue for $5 \mathrm{~min}$ in the chromogen solution from a Vector Laboratories 3,3'diaminobenzidine tetrahydrochloride peroxidase substrate kit.

Quantification. The number of Fos-positive nuclei were counted unilaterally in matched coronal sections from saline- and muscimol-injected rats at three different levels of the rostral $\mathrm{LH}$. The most rostral section was at the level of the suprachiasmatic nuclei, the middle section at the level of the caudal paraventricular hypothalamic nuclei (PVNs), and the 

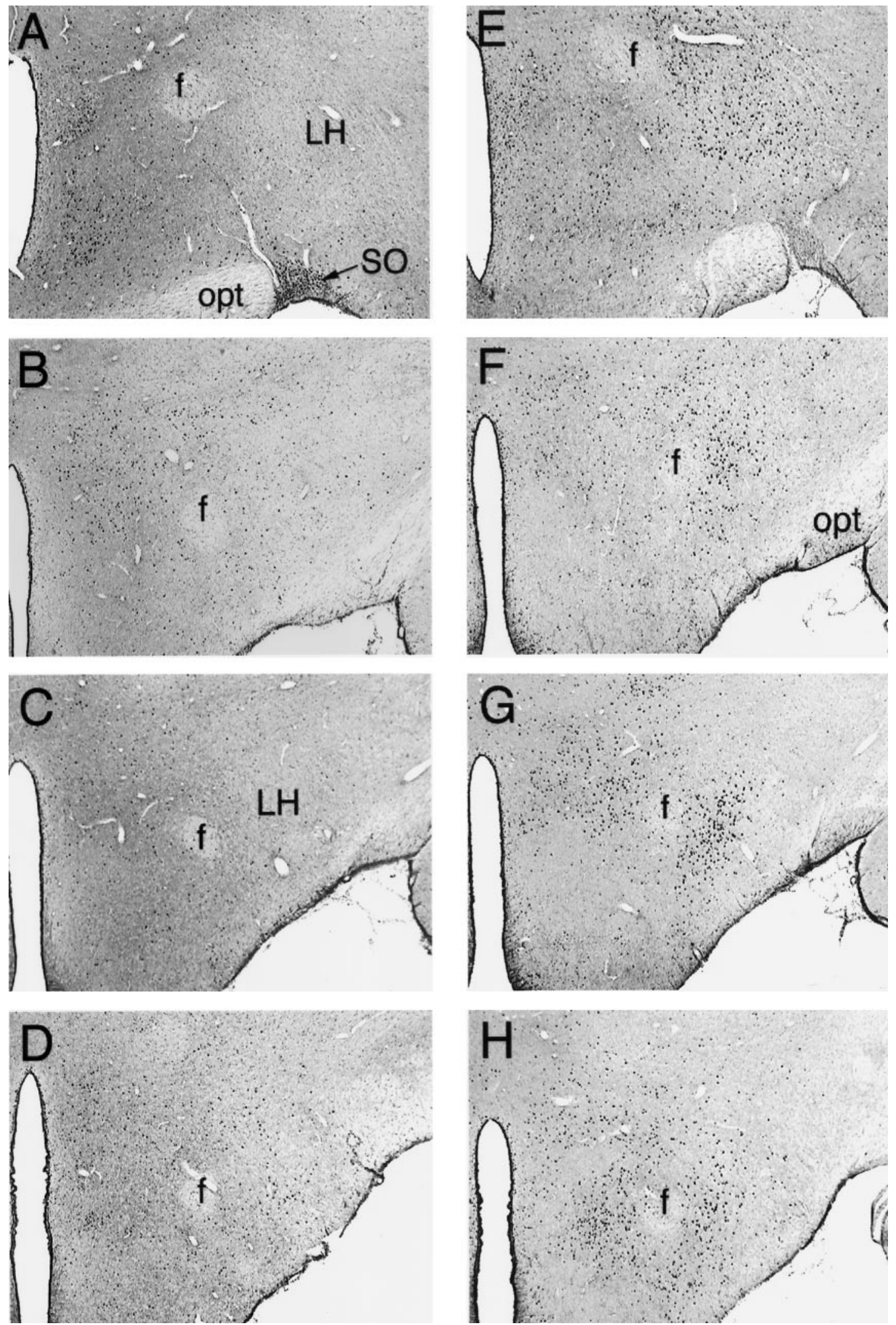

Figure 2. Photomicrographs of Fos-LI in serial coronal sections taken through the central LH after intra-AcbSh injections of saline $(A-D)$ or 100 ng of muscimol $(E-H)$. Muscimol injections greatly increased the number of LH cells demonstrating Fos-LI, particularly in the perifornical region of the LH. SO, Supraoptic nucleus; opt, optic tract; $f$, fornix. Magnification, $40 \times$. 

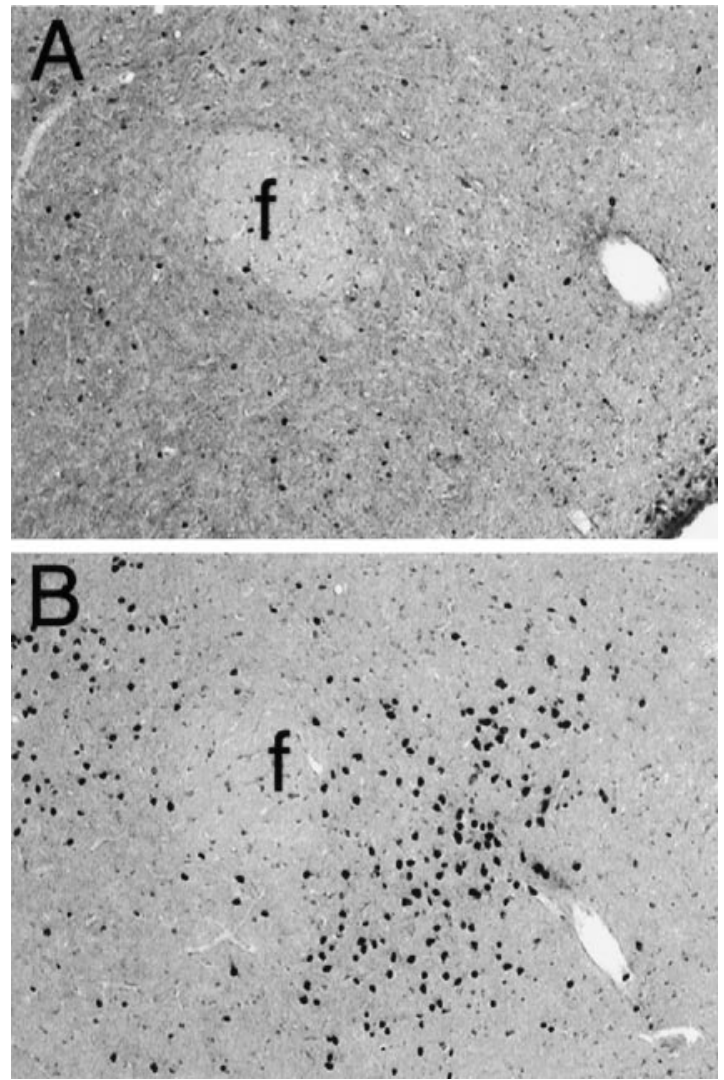

Figure 3. Higher power view of Fig. 1, $C$ and $G$, showing Fos-LI in the LH after intra-AcbSh injections of saline $(A)$ or muscimol $(B)$. $f$, Fornix. Magnification, $100 \times$.

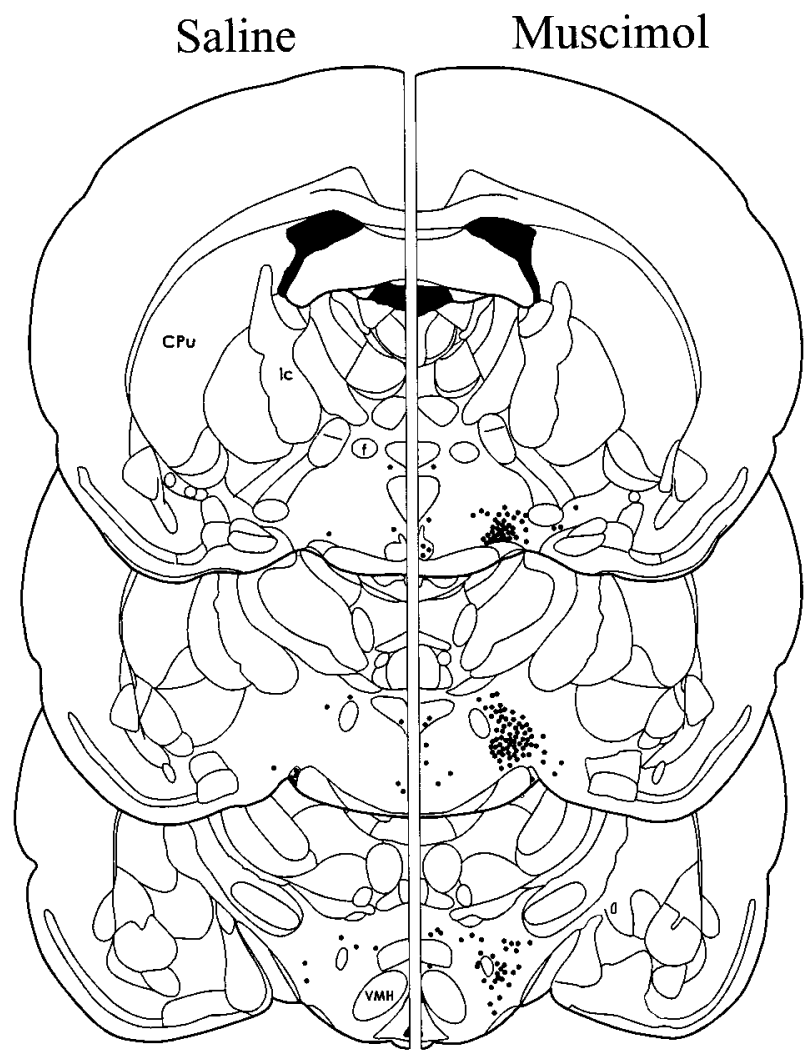

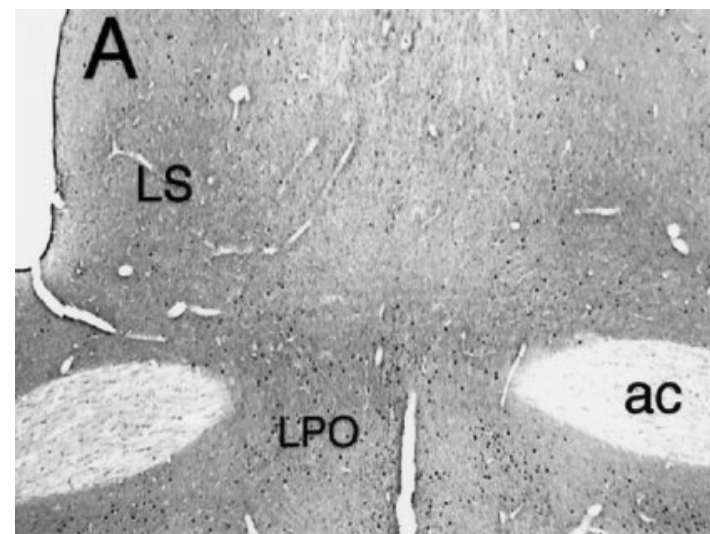

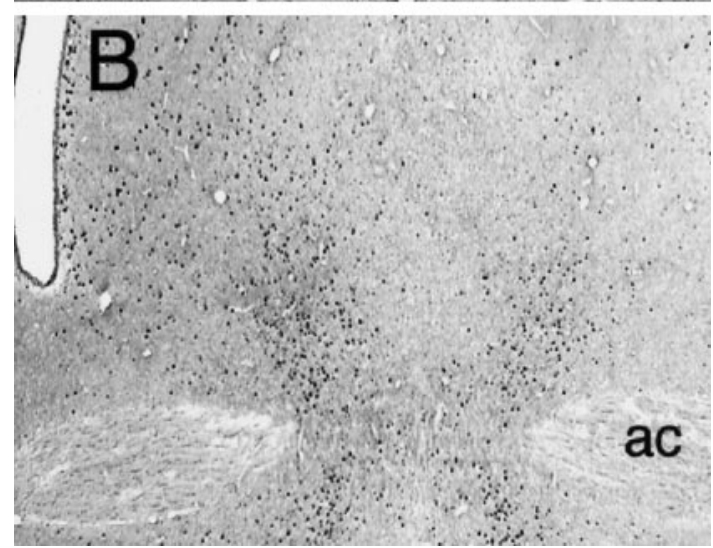

Figure 5. Fos-LI at the level of the lateral septum after intra-AcbSh injections of saline $(A)$ or muscimol $(B)$. Although muscimol increased Fos-LI in cells throughout the LS, the greatest effect was noted in the ventral aspect of the nucleus. $L P O$, Lateral preoptic area; $a c$, anterior commissure. Magnification, $40 \times$.

most caudal section at the level of the dorsomedial hypothalamic nuclei. These levels correspond approximately to plates 23, 25, and 28 of the Paxinos and Watson atlas (1997), respectively.

Statistical analyses. In experiment 1, the mean number of Fosimmunoreactive nuclei were compared at each of the three levels examined using a Student's $t$ test. In experiments 2 and 3, $2 \mathrm{hr}$ food and water intake data were analyzed across doses using a one-factor ANOVA with repeated measures. Where an overall significant effect of dose was found, individual comparisons with the AcbSh-muscimol-LH-vehicle control condition (experiment 2) or vehicle treatment (experiment 3) were examined using Dunnett's multiple comparison method.

\section{RESULTS}

\section{Experiment 1}

A schematic illustration of a typical AcbSh injector placement is given in Figure $1 A$. As we have reported previously, bilateral microinjections of $100 \mathrm{ng}$ of muscimol into the AcbSh elicited intense feeding in satiated rats and greatly increased consumption

Figure 4. Schematic illustration of the mean number and location of cells exhibiting Fos-LI at three levels of the LH. The left depicts Fos-LI after injection of saline into the AcbSh, and the right depicts Fos-LI after injection of muscimol into the AcbSh. Each dot represents approximately five labeled cells. The mean \pm SEM number of hypothalamic cells exhibiting Fos-LI on one side of the brain at each level are as follows: rostral LH: saline $35 \pm 6$, muscimol $377 \pm 50$; middle LH: saline $24 \pm 3$, muscimol $692 \pm 63$; caudal LH: saline $49 \pm 6$, muscimol $322 \pm 40$. Сpu, Caudate putamen; $V M H$, ventromedial hypothalamic nucleus; $i c$, internal capsule; $f$, fornix. 

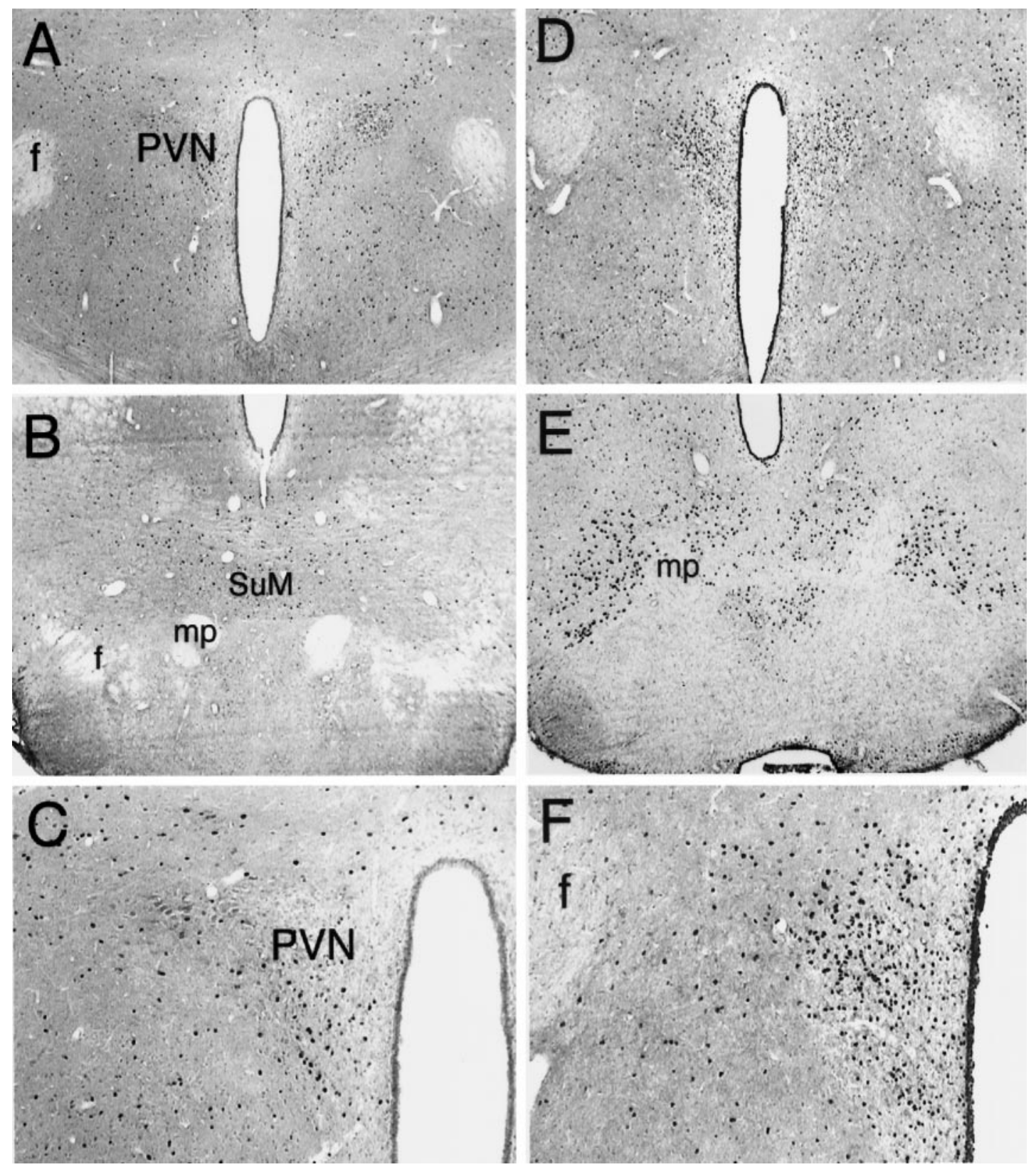

Figure 6. Fos expression in the central $(A, C, D, F)$ and caudal $(B, E)$ hypothalamus after saline $(A-C)$ or muscimol $(D-F)$ injections in the AcbSh. Muscimol greatly increased the number of Fos-positive nuclei in cells located in the PVN and the caudal pole of the LH at the level of the SuM. $C$ and $F$ are higher power views of the PVN. $m p$, Mammillary peduncle; $f$, fornix. Magnification: $A, B, D, E, 40 \times ; C, F, 100 \times$.

of chow over a $2 \mathrm{hr}$ period compared with intake after vehicle injections (vehicle: $1.6 \pm 0.47 \mathrm{gm}$; muscimol: $10.1 \pm 0.74 \mathrm{gm}$ ). Injections of muscimol into the AcbSh also greatly increased the number of cells showing Fos-like immunoreactivity (Fos-LI) in the LH (Figs. 2, 3). Although a significant increase in Fos-LI was observed throughout the rostrocaudal extent of the $\mathrm{LH}$, the largest increase was seen in the perifornical region of the nucleus. Cell counts on comparable LH sections demonstrated that AcbSh injections of muscimol significantly increased the number of neurons exhibiting Fos-LI compared with saline-injected rats $(p<$ 0.001 at each level examined) (Fig. 4).

Large increases in Fos-LI also were observed in a number of brain regions other than the $\mathrm{LH}$, including the lateral septum
(LS) and dorsolateral preoptic region (Fig. 5), the PVN, and the caudal LH- ventral tegmental area (VTA) transition zone in the vicinity of the supramammillary nucleus (SuM) (Fig. 6), the VTA and medial substantia nigra pars compacta (SNC) (Fig. 7), and the NTS (Fig. 8).

\section{Experiment 2}

A schematic illustration of a typical perifornical $\mathrm{LH}$ injector placement is given in Figure $1 \mathrm{~B}$. Simultaneous administration of the $\mathrm{GABA}_{\mathrm{A}}$ receptor agonist muscimol into the AcbSh and saline into the perifornical $\mathrm{LH}$ elicited intense feeding in satiated rats $(p<0.01)$. This feeding response was dose-dependently attenu- 


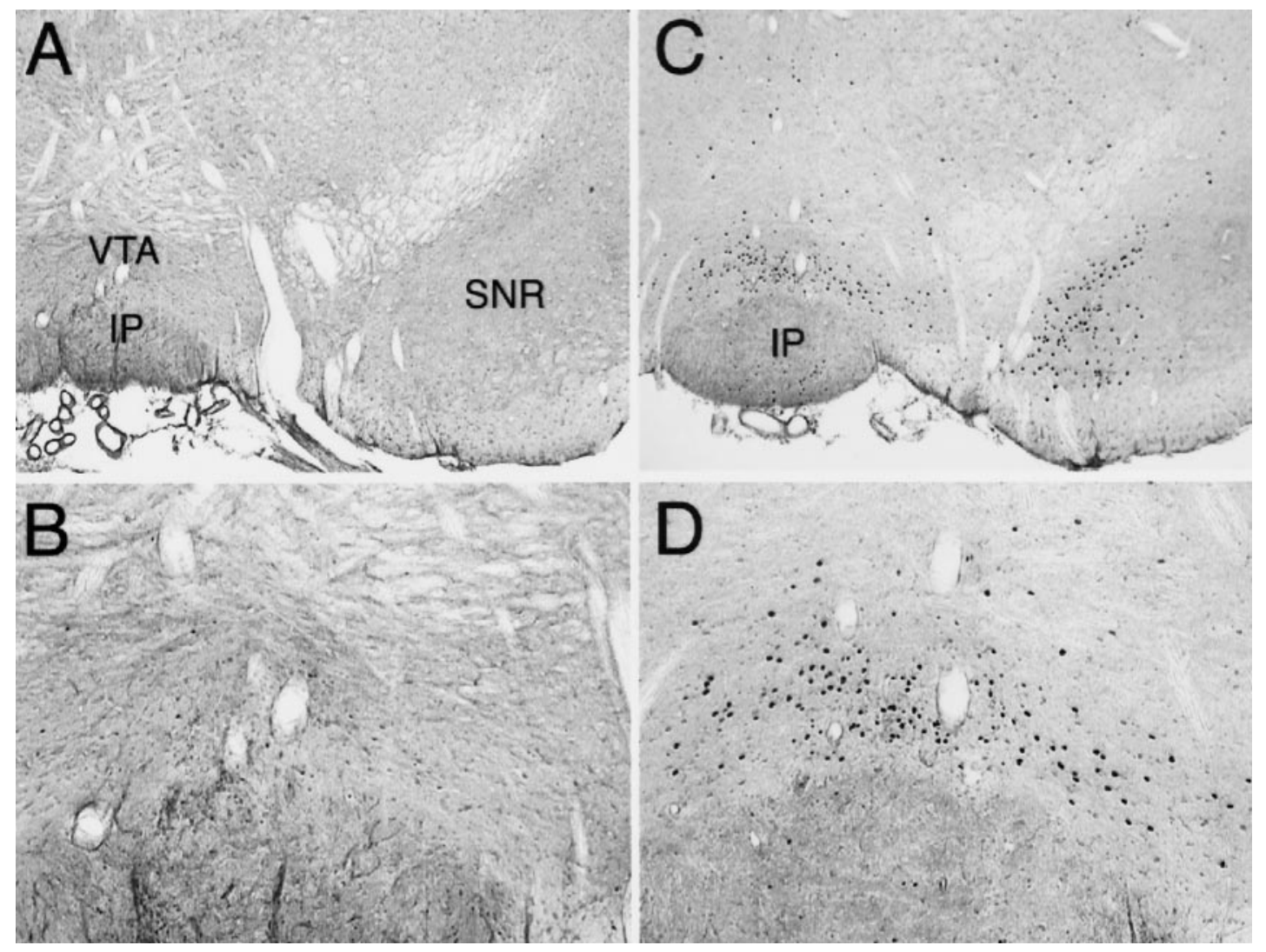

Figure 7. Coronal sections through the midbrain showing Fos-LI after saline $(A, B)$ or muscimol $(C, D)$ inf usion into the AcbSh. Fos expression was increased by muscimol in both the VTA and medial substantia nigra, pars compacta. $I P$, Interpeduncular nucleus; $S N R$, substantia nigra, pars reticulata. Magnification: $A, C, 40 \times ; B, D, 100 \times$.

ated by injections of the selective NMDA antagonist $\mathrm{D}(-)$-AP-5 into the perifornical LH (Fig. 9).

\section{Experiment 3}

Bilateral injections of the selective $\mathrm{GABA}_{\mathrm{A}}$ receptor blocker bicuculline (10-200 ng/side) or the selective $\mathrm{GABA}_{\mathrm{B}}$ receptor blocker saclofen (500 ng/side) did not alter food or water intake significantly in satiated rats (Fig. 10).

\section{DISCUSSION}

Data obtained in this series of experiments provide important evidence of a functional relationship between the AcbSh and $\mathrm{LH}$ as they relate to the control of feeding behavior. Injections of muscimol into the AcbSh greatly increased the synthesis of the nuclear protein Fos in neurons located in the LH. Although the number of neurons expressing Fos-LI was increased significantly throughout the rostrocaudal extent of the LH (Fig. 4), the number of Fos-positive nuclei was greatest in the perifornical LH at the level of the PVN. Because increased synthesis of Fos is generally accepted as a marker for neuronal activation (Sheng and Greenberg, 1990), this result suggests that these cells increase their rate of firing in response to the activation of $\mathrm{GABA}_{\mathrm{A}}$ receptors located on AcbSh neurons. The $\mathrm{LH}$ is well known for playing a critical role in the control of ingestive behavior (for review, see Bernardis and Bellinger, 1996). It is especially interesting that cells in the $\mathrm{LH}$ appear to be activated by application of a GABA agonist to AcbSh neurons, because electrical (Miller, 1960) or chemical (Stanley et al., 1993a,b) excitation of LH neurons is known to induce intense feeding in satiated rats. These data strongly suggest that AcbSh neurons may control feeding behavior through their influence on the firing rate of LH neurons. Our results extend those presented in a recent report in which an increase in LH Fos accompanied the reverse dialysis of muscimol at a site located on the border between the core and shell subregions (Yoshida et al., 1997). Because we verified our injection sites histologically and behaviorally, it appears likely that increased synthesis of Fos in the LH is the result of specifically inhibiting neurons in the AcbSh. Still, it is important to note that this technique does not address the question of whether the AcbSh influences the firing rate of $\mathrm{LH}$ neurons directly through monosynaptic efferents or indirectly through a polysynaptic pathway involving one or more intervening brain structures. Furthermore, although our $90 \mathrm{~min}$ postinjection survival period was chosen to help maximize Fos levels (Müller et al., 1984), it would be interesting to perform a time course analysis of Fos synthesis using shorter survival times to determine how quickly Fos synthesis is stimulated in $\mathrm{LH}$ neurons.

We also noted that injections of muscimol into the AcbSh increased Fos-LI in a number of brain regions in addition to the LH. These areas included the LS (Fig. 5) and PVN (Fig. 6) in the forebrain, the VTA and medial SNC (Fig. 7) in the midbrain, and the NTS (Fig. 8) in the hindbrain. Along with the LH, the LS, PVN, and NTS are well known components of the central circuitry involved in the mediation of feeding behavior (Stanley and Leibowitz, 1985; King and Nance, 1986; Stanley et al., 1988; Tempel et al., 1993; Kotz et al., 1997; Treece et al., 1998; Pu et al., 1999). The fact that manipulations of the AcbSh can alter the 

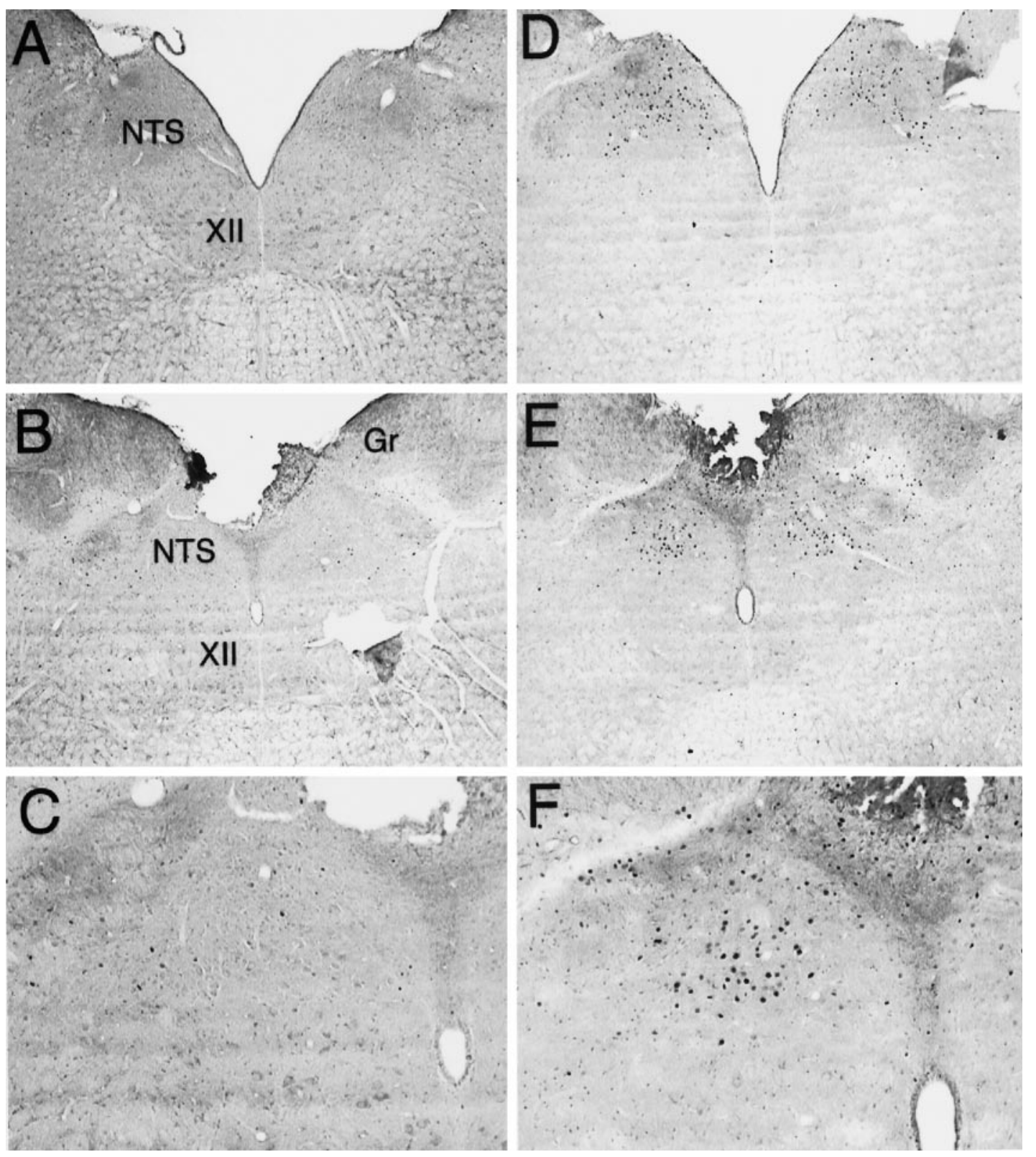

Figure 8. Fos expression at the level of the NTS after intra-AcbSh inf usions of saline $(A-C)$ or muscimol $(D-F)$. The number of cells exhibiting Fos-LI was increased at both intermediate $(A, D)$ and caudal $(B, E)$ levels of the NTS. $C$ and $F$ are higher power views of the caudal NTS. $G r$, Gracile nucleus; $X I I$, hypoglossal nucleus. Magnification: $A, B, D, E, 40 \times ; C, F, 100 \times$.

activity of neurons in these regions reinforces the concept that the medial nucleus accumbens plays an important role in the control of food intake. It is particularly interesting that neurons in the NTS are activated by injections of muscimol into the AcbSh, even in the absence of food intake. This result provides evidence that the medial accumbens can influence neuronal activity at an important hindbrain feeding site thought to be involved in the integration of gustatory and visceral information.

Activation of $\mathrm{GABA}_{\mathrm{A}}$ receptors in the AcbSh also resulted in a small, but relatively consistent, increase in Fos-LI in neurons located in the medial ventral pallidum (VPm). The VPm is one of the primary sites of termination of AcbSh efferents (Heimer et al. 1991) and has been demonstrated recently to play a role in the control of food intake (Stratford et al., 1999). However, evaluation of Fos-LI throughout the ventral pallidum is complicated by the fact that the rostral VPm is located in close proximity to our muscimol injection site. Intracerebral injections often result in Fos synthesis by neurons surrounding the infusion site, and the extent to which this phenomenon contributed to labeling in the $\mathrm{VPm}$ is currently unclear.

Interestingly, muscimol injections in the AcbSh increased the expression of Fos in the VTA and medial SNC, two sites from which dopaminergic mesolimbic projections terminating in the AcbSh and other areas of the forebrain originate. The VTA and medial SNC are innervated by monosynaptic projections from the AcbSh (Heimer et al., 1991), and the observed increase in Fos-LI probably reflects a disinhibition of neurons in the region. Although it is not yet known whether the activated cells are dopaminergic, the results suggest that inhibiting cells in the AcbSh may increase forebrain levels of dopamine. Thus, in addition to a 


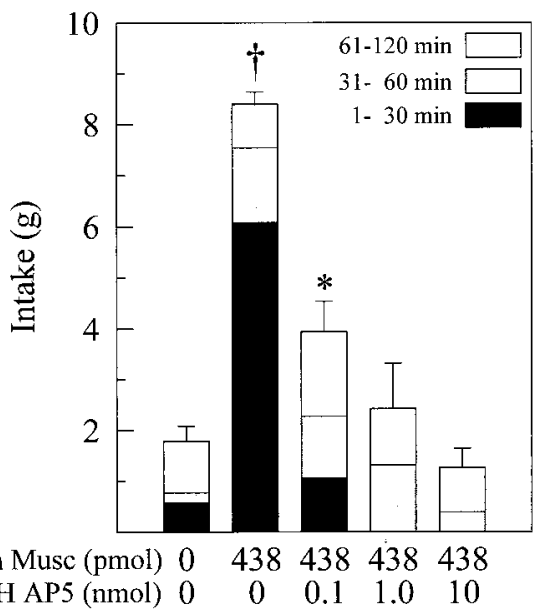

Figure 9. Mean \pm SEM food intake after simultaneous bilateral injections of muscimol into the AcbSh and various doses of AP-5 into the perifornical lateral hypothalamus. AP-5 dose-dependently suppressed muscimol-elicited food intake. ${ }^{*} p<0.05 ; \dagger p<0.01$, significant difference from control trial.

behaviorally specific effect on food intake, manipulations of the AcbSh may prove to have more general effects on neural systems subserving reward and reinforcement.

As part of an ongoing series of studies that have elucidated the importance of glutamatergic systems in the LH for the control of food intake, Stanley et al. (1996) have demonstrated that activation of NMDA receptors in the LH is necessary for the full expression of feeding induced by food deprivation. Similarly, the current study shows that blocking LH NMDA receptors with the selective antagonist $\mathrm{D}(-)-\mathrm{AP}-5$ can potently suppress feeding elicited by injections of muscimol into the AcbSh. This strongly suggests that the expression of feeding behavior elicited by inhibition of neurons in the AcbSh depends on an NMDA receptormediated activation of $\mathrm{LH}$ neurons. It also raises the possibility that inhibition of cells in the AcbSh and food deprivation induce feeding through activation of a common neural pathway involving neurons in the $\mathrm{LH}$.

The question arises as to whether the LH cells are under direct control of AcbSh neurons or whether information from the AcbSh is relayed transynaptically through one or more intervening nuclei. Because the axons of some projection neurons located in the AcbSh terminate in the LH (Heimer et al., 1991; Zahm and Brog, 1992; Kirouac and Ganguly, 1995) and because most AcbSh projection neurons are thought to use GABA as a neurotransmitter (Meredith et al., 1993), the most parsimonious route of control would be through a direct GABAergic projection from the AcbSh to the LH. In this case, inhibition of AcbSh projection neurons by activation of dendritic and/or somatic $\mathrm{GABA}_{\mathrm{A}}$ receptors would suppress the release of GABA from fibers terminating in the LH. This, in turn, would disinhibit LH neurons, resulting in an increase in food intake. If this model were correct, then blocking GABA receptors in the $\mathrm{LH}$ should have similar behavioral results and should result in an acute increase in food intake. We found that the selective blockade of $\mathrm{GABA}_{\mathrm{A}}$ or $\mathrm{GABA}_{\mathrm{B}}$ receptors in the region had no effect on food or water intakes. This is persuasive evidence that a tonically inhibitory feeding-related GABAergic projection originating in the AcbSh, or anywhere else, does not terminate in the region of the $\mathrm{LH}$ we know to be activated by our manipulations of the AcbSh. The possibility remains, of

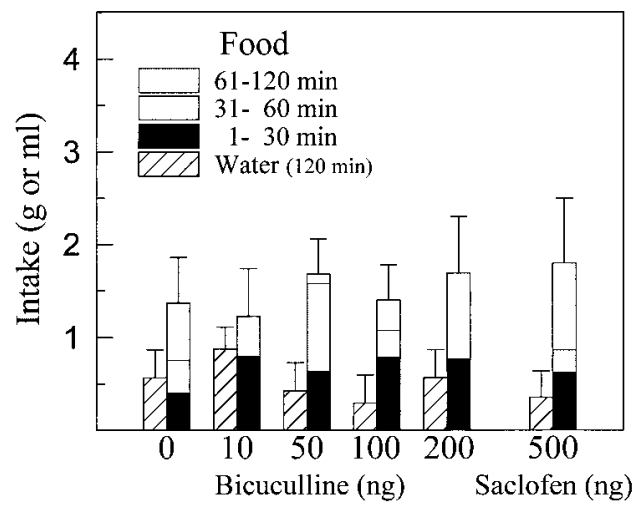

Figure 10. Mean \pm SEM food and water intake after injection of various doses of GABA receptor blockers into the perifornical LH. Neither food nor water intake was significantly altered by blockade of $\mathrm{GABA}_{\mathrm{A}}$ receptors with bicuculline or $\mathrm{GABA}_{\mathrm{B}}$ receptors with saclofen in the $\mathrm{LH}$.

course, that a direct AcbSh-LH projection using some other neurotransmitter is involved. An additional possibility is that GABA in the LH is involved in the control of intake of specific macronutrients. In fact, an early study reported that injections of bicuculline methiodide into the $\mathrm{LH}$ did increase intake of a diet high in fat and carbohydrates during the initial $30 \mathrm{~min}$ of a $3 \mathrm{hr}$ test (Kelly et al., 1977). It is important to reiterate, however, that under the same test conditions in which manipulations of the AcbSh elicit such large increases in food intake (120 min intake of the maintenance diet in non-deprived rats), injections of GABA antagonists into the specific region of the $\mathrm{LH}$ in which we saw the largest increases in Fos expression and in which administration of an NMDA receptor antagonist blocked AcbSh-mediated feeding, did not increase food intake.

In summary, the feeding elicited by injecting muscimol into the AcbSh is accompanied by an increase in the synthesis of Fos in neurons located in the LH, suggesting that these cells are increasing their firing rates in response to the stimulus. Furthermore, the NMDA receptor-mediated activation of $\mathrm{LH}$ neurons is necessary for the expression of the AcbSh-mediated feeding. Neurons in the AcbSh, however, do not appear to control the firing rate of $\mathrm{LH}$ neurons through a direct GABAergic projection to the $\mathrm{LH}$. We have discovered recently that blocking GABA receptors in the medial ventral pallidum, a brain region anatomically interposed between the AcbSh and $\mathrm{LH}$, induces robust feeding in rats (Stratford et al., 1999). Together with our current results, the data raise the interesting possibility that an AcbSh-VPm-LH circuit is involved in the control of food intake.

\section{REFERENCES}

Bernardis LL, Bellinger LL (1996) The lateral hypothalamic area revisited: ingestive behavior. Neurosci Biobehav Rev 20:189-287.

Delgado J, Anand BK (1953) Increases in food intake induced by electrical stimulation of the lateral hypothalamus. Am J Physiol 172:162-168.

Heimer L, Zahm DS, Churchill L, Kalivas PW, Wohltmann C (1991) Specificity in the projection patterns of accumbal core and shell in the rat. Neuroscience 41:89-125.

Ikemoto S, Panksepp J (1996) Dissociations between appetitive and consummatory responses by pharmacological manipulations of rewardrelevant brain regions. Behav Neurosci 110:331-345.

Kelly J, Alheid GF, Newberg A, Grossman SP (1977) GABA stimulation and blockade in the hypothalamus and midbrain: effects on feeding and locomotor activity. Pharmacol Biochem Behav 7:537-541.

King TR, Nance DM (1986) Neuroestrogenic control of feeding behav- 
ior and body weight in rats with kainic acid lesions of the lateral septal area. Physiol Behav 37:475-481.

Kirouac GJ, Ganguly PK (1995) Topographical organization in the nucleus accumbens of afferents from the basolateral amygdala and efferents to the lateral hypothalamus. Neuroscience 67:625-630.

Kotz CM, Billington CJ, Levine AS (1997) Opioids in the nucleus of the solitary tract are involved in feeding in the rat. Am J Physiol 272:R1028-R1032.

Maldonado-Irizarry CS, Swanson CJ, Kelley AE (1995) Glutamate receptors in the nucleus accumbens shell control feeding behavior via the lateral hypothalamus. J Neurosci 15:6779-6788.

Meredith GE, Wouterlood FG (1991) Synaptic organization of nucleus accumbens (ventral striatum). In: The basal ganglia III: advances in behavioral biology, Vol 39 (Carpenter MB, Di Chiara G, Morelli M, Stanzione P, eds), pp 167-176. New York: Plenum.

Meredith GE, Pennartz CM, Groenewegen HJ (1993) The cellular framework for chemical signalling in the nucleus accumbens. Prog Brain Res 99:3-24.

Miller NE (1960) Motivational effects of brain stimulation and drugs. Fed Proc 19:846-854.

Müller R, Bravo R, Burckhardt J, Curran T (1984) Induction of c-fos gene and protein by growth factors precedes activation of $c-m y c$. Nature 312:716-720.

Paxinos G, Watson C (1997) The rat brain in stereotaxic coordinates. San Diego: Academic.

Pu S, Jain MR, Horvath TL, Diano S, Kalra PS, Kalra SP (1999) Interactions between neuropeptide $\mathrm{Y}$ and gamma-aminobutyric acid in stimulation of feeding: a morphological and pharmacological analysis. Endocrinology 140:933-940.

Salamone JD (1994) The involvement of nucleus accumbens dopamine in appetitive and aversive motivation. Behav Brain Res 61:117-133.

Sheng M, Greenberg ME (1990) The regulation and function of c-fos and other immediate early genes in the nervous system. Neuron 4:477-485.

Stanley BG, Leibowitz SF (1985) Neuropeptide Y injected in the paraventricular hypothalamus: a powerful stimulant of feeding behavior. Proc Natl Acad Sci USA 82:3940-3943.
Stanley BG, Lanthier D, Leibowitz SF (1988) Multiple brain sites sensitive to feeding stimulation by opioid agonists: a cannula-mapping study. Pharmacol Biochem Behav 31:825-832.

Stanley BG, Ha LH, Spears LC, Dee II MG, (1993a) Lateral hypothalamic injections of glutamate, kainic acid, D,L- $\alpha$-amino3-hydroxy-5methyl-isoxazole propionic acid or $N$-methyl-D-aspartic acid rapidly elicit intense transient eating in rats. Brain Res 613:88-95.

Stanley BG, Willett III VL, Donias HW, Ha LH, Spears LC (1993b) The lateral hypothalamus: a primary site mediating excitatory amino acidelicited eating. Brain Res 630:41-49.

Stanley BG, Willett III VL, Donias HW, Dee II MG, Duva MA (1996) Lateral hypothalamic NMDA receptors and glutamate as physiological mediators of eating and weight control. Am J Physiol 270:R443-R449.

Stratford TR, Kelley AE (1997a) Feeding elicited by inhibition of neurons in the nucleus accumbens shell depends on activation of neurons in the lateral hypothalamus. Soc Neurosci Abstr 23:577.

Stratford TR, Kelley AE (1997b) GABA in the nucleus accumbens shell participates in the central regulation of feeding behavior. J Neurosci 17:4434-4440.

Stratford TR, Swanson CJ, Kelley AE (1998) Specific changes in food intake elicited by blockade or activation of glutamate receptors in the nucleus accumbens shell. Behav Brain Res 93:43-50.

Stratford TR, Kelley AE, Simansky KJ (1999) Blockade of GABA receptors in the medial ventral pallidum elicits feeding in satiated rats. Brain Res 825:199-203.

Tempel DL, Kim T, Leibowitz SF (1993) The paraventricular nucleus is uniquely responsive to the feeding stimulatory effects of steroid hormones. Brain Res 614:197-204.

Treece BR, Covasa M, Ritter RC, Burns GA (1998) Delay in meal termination follows blockade of $N$-methyl-D-aspartate receptors in the dorsal hindbrain. Brain Res 810:34-40.

Yoshida M, Yokoo H, Nakahara K, Tomita M, Hamada N, Ishikawa M, Hatakeyama J, Tanaka M, Nagatsu I (1997) Local muscimol disinhibits mesolimbic dopaminergic activity as examined by brain microdialysis and Fos immunohistochemistry. Brain Res 767:356-360.

Zahm DS, Brog JS (1992) On the significance of subterritories in the "accumbens" part of the rat ventral striatum. Neuroscience 50:751-767. 